\title{
Membrane Stabilizing And Antimicrobial Activities Of Caladium Bicolor And Chenopodium Album
}

\author{
Mohammad Kamruzzaman Biswas ${ }^{1}$, Shakil Ahammad Mridha ${ }^{1}$, Mohammad A. \\ Rashid $^{2}$ and Tasnuva Sharmin ${ }^{1}$ \\ ${ }^{1}$ Department of Pharmacy, State University of Bangladesh, Dhaka-1205, Bangladesh \\ ${ }^{2}$ Phytochemical Research Laboratory, Department of Pharmaceutical Chemistry, \\ Faculty of Pharmacy, University of Dhaka, Dhaka-1000, Bangladesh
}

\begin{abstract}
The crude methanol extracts of whole plant of Caladium bicolor (Aiton) Vent. and leaf of Chenopodium album $L$. as well as their pet-ether, carbon tetrachloride, chloroform and aqueous soluble fractions were evaluated for membrane stabilizing and antimicrobial activities. At concentration $1.0 \mathrm{mg} / \mathrm{ml}$, the carbon tetrachloride soluble fraction of C. bicolor inhibited $43.92 \pm 1.63 \%$ and $38.08 \pm 0.83 \%$ hypotonic solution and heat induced haemolysis of RBCs, respectively. Among the extractives of C. album, the aqueous soluble fraction inhibited $47.11 \pm 0.49 \%$ and $36.73 \pm 0.76 \%$ hypotonic solution and heat induced haemolysis of RBCs as compared to $72.79 \%$ and $42.12 \%$ by acetyl salicylic acid $(0.10 \mathrm{mg} / \mathrm{ml})$, respectively. C. bicolor test samples demonstrated zone of inhibition ranging from 6.0 to $20.0 \mathrm{~mm}$. The chloroform soluble fraction showed the highest zone of inhibition $(20.0 \mathrm{~mm})$ against Staphylococcus aureus. The test samples of C. album displayed zone of inhibition ranging from 7.0 to $13.0 \mathrm{~mm}$. The highest zone of inhibition $(13.0 \mathrm{~mm})$ was showed by the chloroform soluble fraction against Salmonella paratyphi.
\end{abstract}

Keywords- Caladium bicolor (Aiton) Vent., Chenopodium album L., membrane stabilizing activity, hypotonic solution, disc diffusion method, zone of inhibition

\section{Introduction}

According to the World Health Organization (WHO), $80 \%$ of the world's populations rely on traditional medicines [1]. (Adamu et al., 2004). The practice of herbal medicine is common in rural areas where western medicines are too expensive or not available [1]. Humans have frequently used plants to treat common infectious diseases and some of these traditional medicines are still part of the habitual treatment of various maladies. It has been reported that 115 articles were published on the antimicrobial activity of medicinal plants in Pubmed during the period between 1966-1994, but in the following decade, between 1995 and 2004, 307 were published [2]. The demand for more and more drugs from plant sources is continuously increasing. It is therefore essential for systematic evaluation of plants used in traditional medicine for various ailments. Hence, there is need to screen medicinal plants for promising biological activity [3]. Drugs derived from unmodified natural products or drugs semi-synthetically obtained from natural sources corresponded to $78 \%$ of the new drugs approved by the FDA between 1983 and 1994 [4].

Caladium bicolor (Aiton) Vent. (Synonyms: C. picturatum, C. marmoratum) commonly known as fancy leaf caladium, elephant's ear and hear of jesus, is flowering herb in the plant family Araceae. It is found from coastal Brazil to the Andes Mountains and north to the Guianas and Panama [5]. C. bicolor is found in Trinidad, an island very close to the South American mainland, and from the great variation found in the plants [6], the species appears to be native there. An infusion of fresh leaf is used for the treatment of angina. The powdered dried leaf is used to treat infected sores [7].

Chenopodium album L. (Synonyms: Anserina candidans Lam. Montandon., Atriplex alba L. Crantz, Bengali name: betho shaak) commonly known as lamb's quarters, melde, goosefoot and fat-hen, is a fastgrowing weedy annual plant belonging to the Amaranthaceae family. Though cultivated in some regions, the plant is elsewhere considered a weed. The plant's native range includes most of Europe and is widely introduced in Africa, Australasia and North America. The plant improves appetite, acts as anthelmintic, laxative, diuretic and tonic. It is also used in abdominal pain, piles and eye disease [8].

As part of our ongoing investigations on medicinal plants of Bangladesh [9-14], the crude methanol extracts of whole plant of $C$. bicolor and leaves of $C$. album growing in Bangladesh as well as their organic and aqueous soluble fractions were studied for membrane stabilizing and antimicrobial activities for the first time and we, here in, report the results of our preliminary investigations. 


\section{Materials and methods}

2.1 Plant materials

The whole plant of $C$. bicolor and leaves of $C$. album were collected from Mirpur Botanical garden, Dhaka in January 2012. Voucher specimens for $C$. bicolor and C. album have been maintained in Bangladesh National Herbarium, Dhaka Bangladesh for future references.

The collected plant materials were cleaned, sun dried and pulverized. The powdered materials (650 g each) of both the plants were separately soaked in 1.5 liters of methanol at room temperature for 7 days. The extracts were filtered through fresh cotton bed and finally with Whatman filter paper number 1 and concentrated with a rotary evaporator at $40^{\circ}-45^{\circ} \mathrm{C}$ temperature and pressure. An aliquot $(5 \mathrm{~g})$ of each of the concentrated methanol extracts was fractionated by the modified Kupchan partition protocol [15] and the resultant partitionates were evaporated to dryness with rotary evaporator to yield pet-ether (PESF), carbon tetrachloride (CTCSF), chloroform (CSF) and aqueous (AQSF) soluble materials (Table 1). The residues were then stored in a refrigerator until further use.

Table 1. Kupchan partitioning of C. bicolor and C. album

\begin{tabular}{|c|c|c|c|}
\hline $\begin{array}{l}\text { Crude } \\
\text { Fractions }\end{array}$ & extract/ & $\begin{array}{l}\text { C. bicolor } \\
\text { (g) }\end{array}$ & $\begin{array}{l}\text { C. album } \\
\text { (g) }\end{array}$ \\
\hline $\mathrm{Me}$ & & 5.0 & 5.0 \\
\hline PESF & & 1.0 & 1.0 \\
\hline CTCSF & & 0.8 & 1.8 \\
\hline $\mathrm{CSF}$ & & 1.2 & 1.0 \\
\hline AQSF & & 1.5 & 0.5 \\
\hline
\end{tabular}

$\mathrm{ME}=$ Methanolic crude extract; $\mathrm{PESF}=$ Pet-ether soluble fraction; $\mathrm{CTCSF}=\mathrm{Car}$. fraction; $\mathrm{CSF}=\mathrm{Chloroform}$ soluble fraction; $\mathrm{AQSF}=$ Aqueous soluble fraction.

\subsection{Membrane stabilizing activity}

The membrane stabilizing activity of the extractives was assessed by using hypotonic solution- and heat-induced haemolysis of human erythrocyte by the method developed by Omale and Okafor (2008) [16].

\subsubsection{Hypotonic solution-induced haemolysis}

The test sample consisted of stock erythrocyte $(\mathrm{RBC})$ suspension $(0.50 \mathrm{ml})$ mixed with $4.5 \mathrm{ml}$ of hypotonic solution $(50 \mathrm{mM} \mathrm{NaCl})$ in $10 \mathrm{mM}$ sodium phosphate buffered saline ( $\mathrm{pH} 7.4)$ containing either the extract $(2.0 \mathrm{mg} / \mathrm{ml})$ or acetyl salicylic acid $(0.1 \mathrm{mg} / \mathrm{ml})$. The control sample consisted of $0.5 \mathrm{ml}$ of RBCs suspension mixed with hypotonic buffered saline alone. The mixture was incubated for 10 minutes at room temperature, centrifuged for 10 minutes at $3000 \mathrm{~g}$ and the absorbance of the supernatant was measured at 540 $\mathrm{nm}$. The percentage inhibition of haemolysis was calculated using the following equation-

$\%$ Inhibition of haemolysis $=100 \times\left(\mathrm{OD}_{1}-\mathrm{OD}_{2} / \mathrm{OD}_{1}\right)$,

where, $\mathrm{OD}_{1}=$ optical density of hypotonic buffered saline solution alone (control) and $\mathrm{OD}_{2}=$ optical density of test sample in hypotonic solution.

\subsubsection{Heat induced haemolysis}

Isotonic buffer containing aliquot $(5 \mathrm{ml})$ of the different extractives was put into two duplicate sets of centrifuge tubes. The vehicle, in the same amount, was added to another tube as control. Erythrocyte suspension $(30 \mu \mathrm{l})$ was added to each tube and mixed gently by inversion. One set of the tubes was incubated at $54{ }^{\circ} \mathrm{C}$ for 20 minute in a water bath, while the other set was maintained at $0^{\circ}-5^{\circ} \mathrm{C}$ in an ice bath. The reaction mixture was centrifuged for 3 minutes at $1300 \mathrm{~g}$ and the absorbance of the supernatant was measured at $540 \mathrm{~nm}$. Then the percentage inhibition or acceleration of haemolysis was calculated according to the following equation:

$\%$ Inhibition of haemolysis $=100 \times\left[1-\left(\mathrm{OD}_{2}-\mathrm{OD}_{1} / \mathrm{OD}_{3}-\mathrm{OD}_{1}\right)\right]$

where, $\mathrm{OD}_{1}=$ optical density of unheated test sample, $\mathrm{OD}_{2}=$ optical density of heated test sample and $\mathrm{OD}_{3}=$ optical density of heated control sample

\subsection{Antimicrobial screening}

Antimicrobial activity was determined by disc diffusion method [17]. In this classical method, antibiotics diffuse from a confined source through the nutrient agar gel and create a concentration gradient. Dried and sterilized filter paper discs $(6 \mathrm{~mm}$ diameter) containing the test samples of known amounts (400 $\mu \mathrm{g} /$ disc) are placed on nutrient agar medium uniformly seeded with the test microorganisms. Standard antibiotic (Ciprofloxacin) discs $(30 \mu \mathrm{g} / \mathrm{disc})$ and blank discs are used as positive and negative control. These plates are kept at low temperature $\left(4^{\circ} \mathrm{C}\right)$ for 24 hours to allow maximum diffusion of the test materials to the surrounding media. The plates are then inverted and incubated at $37^{\circ} \mathrm{C}$ for 24 hours for optimum growth of the organisms. The test materials having antimicrobial property inhibit microbial growth in the media surrounding the discs and 
thereby yield a clear, distinct area defined as zone of inhibition. The antimicrobial activity of the test agent is then determined by measuring the diameter of zone of inhibition expressed in millimeter.

\section{Statistical analysis}

For all bioassays, three replicates of each sample were used for statistical analysis and the values are reported as mean $\pm \mathrm{SD}$.

Table 2: Effect of different extractives of $C$. bicolor and $C$. album on hypotonic solution and heat--induced haemolysis of erythrocyte membrane

\begin{tabular}{|c|c|c|c|c|}
\hline \multirow[b]{3}{*}{$\begin{array}{l}\text { Samples/ } \\
\text { Standard }\end{array}$} & \multicolumn{4}{|c|}{ \% Inhibition of haemolysis } \\
\hline & \multicolumn{2}{|c|}{ C. bicolor } & \multicolumn{2}{|l|}{ C. album } \\
\hline & $\begin{array}{l}\text { Hypnotic } \\
\text { solution } \\
\text { induced }\end{array}$ & $\begin{array}{l}\text { Heat } \\
\text { induced }\end{array}$ & $\begin{array}{l}\text { Hypnotic } \\
\text { solution } \\
\text { induced }\end{array}$ & $\begin{array}{l}\text { Heat } \\
\text { induced }\end{array}$ \\
\hline $\mathrm{ME}$ & $36.80 \pm 2.05$ & $35.40 \pm 0.62$ & $14.71 \pm 0.26$ & $16.36 \pm 0.38$ \\
\hline PESF & $39.28 \pm 2.06$ & $37.32 \pm 0.11$ & $12.50 \pm 0.33$ & $24.48 \pm 0.82$ \\
\hline CTCSF & $43.92 \pm 1.63$ & $38.08 \pm 0.83$ & $35.57 \pm 0.01$ & $19.71 \pm 0.71$ \\
\hline CSF & $30.11 \pm 0.88$ & $31.51 \pm 0.45$ & $26.92 \pm 0.64$ & $35.08 \pm 0.37$ \\
\hline AQSF & - & - & $47.11 \pm 0.49$ & $36.73 \pm 0.76$ \\
\hline ASA & $72.79 \pm 0.47$ & $42.12 \pm 0.23$ & $72.79 \pm 0.47$ & $42.12 \pm 0.23$ \\
\hline
\end{tabular}

ME = Methanolic crude extract; PESF $=$ Pet-ether soluble fraction; CTCSF $=$ Carbon tetrachloride soluble fraction; $\mathrm{CSF}=\mathrm{Chloroform}$ soluble fraction; $\mathrm{AQSF}=$ Aqueous soluble fraction; $\mathrm{ASA}=$ Acetyl salicylic acid

Table 3: Antimicrobial activity of C. bicolor

\begin{tabular}{lllc}
\hline \multirow{2}{*}{ Test microorganisms } & \multicolumn{3}{l}{ Diameter of zone of inhibition (mm) } \\
\cline { 2 - 4 } & CTCSF & CSF & Ciprofloxacin \\
\hline Bacillus cereus & $9.0 \pm 0.54$ & $8.0 \pm 0.57$ & $45.0 \pm 2.01$ \\
B. megaterium & - & - & $42.0 \pm 1.17$ \\
B. subtilis & $8.0 \pm 0.90$ & - & $42.0 \pm 0.73$ \\
Sarcina lutea & $14.0 \pm 0.44$ & $8.0 \pm 0.61$ & $42.0 \pm 0.23$ \\
Staphylococcus aureus & $7.0 \pm 0.81$ & $20.0 \pm 0.42$ & $42.0 \pm 0.56$ \\
Escherichia coli & - & $8.0 \pm 0.35$ & $42.0 \pm 0.43$ \\
Pseudomonas & $13.0 \pm 0.41$ & $9.0 \pm 0.71$ & $42.0 \pm 1.11$ \\
aeruginosa & $10.0 \pm 0.23$ & $10.0 \pm 0.69$ & \\
Salmonella typhi & - & $10.0 \pm 0.53$ & $45.0 \pm 0.73$ \\
S. paratyphi & - & $12.0 \pm 1.03$ & $47.0 \pm 2.33$ \\
Shigella boydii & $8.0 \pm 0.77$ & $10.0 \pm 0.22$ & $34.0 \pm 0.58$ \\
S. dysenteriae & - & $6.0 \pm 0.15$ & $42.0 \pm 0.22$ \\
Vibrio mimicus & $10.0 \pm 0.46$ & $12.0 \pm 0.55$ & $40.0 \pm 0.45$ \\
V. parahaemolyticus & $7.0 \pm 0.53$ & $8.0 \pm 0.67$ & $35.0 \pm 0.44$ \\
Candida albicans & $10.0 \pm 0.12$ & $9.0 \pm 0.92$ & $38.0 \pm 0.49$ \\
Aspergillus niger & $8.0 \pm 0.43$ & $8.0 \pm 0.47$ & $37.0 \pm 0.33$ \\
Sacharomyces cerevacae & & & $38.0 \pm 0.11$ \\
\hline
\end{tabular}

$\mathrm{CTCSF}=$ Carbon tetrachloride soluble fraction; $\mathrm{CSF}=$ Chloroform soluble fraction, - indicates no zone of inhibition

Table 4: Antimicrobial activity of $C$. album.

\begin{tabular}{lllc}
\hline \multirow{2}{*}{ Test microorganisms } & & \multicolumn{2}{l}{ Diameter of zone of inhibition (mm) } \\
\cline { 2 - 4 } & CTCSF & CSF & Ciprofloxacin \\
\hline Bacillus cereus & - & $9.0 \pm 0.57$ & $45.0 \pm 2.01$ \\
B. megaterium & - & $8.0 \pm 0.38$ & $42.0 \pm 1.17$ \\
B. subtilis & - & $11.0 \pm 0.46$ & $42.0 \pm 0.73$ \\
Sarcina lutea & - & $10.0 \pm 0.61$ & $42.0 \pm 0.23$ \\
Staphylococcus aureus & - & $8.0 \pm 0.42$ & $42.0 \pm 0.56$ \\
Escherichia coli & - & $9.0 \pm 0.35$ & $42.0 \pm 0.43$ \\
Pseudomonas aeruginosa & - & $9.0 \pm 0.71$ & $42.0 \pm 1.11$ \\
Salmonella typhi & $7.0 \pm 0.23$ & $9.0 \pm 0.69$ & $45.0 \pm 0.73$ \\
S. paratyphi & $8.0 \pm 0.77$ & $13.0 \pm 0.53$ & $47.0 \pm 2.33$ \\
Shigella boydii & - & $8.0 \pm 1.03$ & $34.0 \pm 0.58$ \\
S. dysenteriae & - & $10.0 \pm 0.22$ & $42.0 \pm 0.22$ \\
Vibrio mimicus & - & $8.0 \pm 0.15$ & $40.0 \pm 0.45$ \\
V. parahaemolyticus & - & $8.0 \pm 0.55$ & $35.0 \pm 0.44$
\end{tabular}

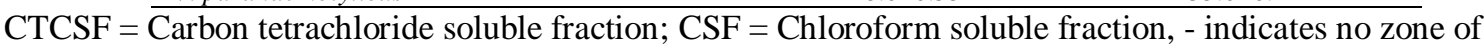
inhibition 


\section{Results and discussion}

The aim of the study was to evaluate the crude methanol extracts of $C$. bicolor and $C$. album as well as their pet-ether, carbon tetrachloride, chloroform and aqueous soluble fractions for membrane stabilizing and antimicrobial activities.

At concentration $1.0 \mathrm{mg} / \mathrm{ml}$, C. bicolor and C. album extractives significantly protected the haemolysis of RBC induced by hypotonic solution and heat as compared to the standard acetyl salicylic acid $(0.10 \mathrm{mg} / \mathrm{ml})$. The carbon tetrachloride soluble fraction of $C$. bicolor inhibited $43.92 \pm 1.63 \%$ and $38.08 \pm 0.83 \%$ hypotonic solution and heat induced haemolysis of RBCs, respectively. The aqueous soluble fraction of $C$. album inhibited $47.11 \pm 0.49 \%$ and $36.73 \pm 0.76 \%$ hypotonic solution and heat induced haemolysis of RBCs as compared to $72.79 \%$ and $42.12 \%$ by acetyl salicylic acid, respectively (Table 2 ).

C. bicolor test samples were evaluated against five gram positive and eight gram negative bacteria and three fungi to screen their microbial growth inhibitory potentials. The carbon tetrachloride and the chloroform soluble fractions demonstrated zone of inhibition ranging from 6.0 to $20.0 \mathrm{~mm}$. The highest zone of inhibition $(20.0 \mathrm{~mm})$ was showed by the chloroform soluble fraction against Staphylococcus aureus. The carbon tetrachloride soluble fraction exhibited $14.0 \mathrm{~mm}$ zone of inhibition against Sarcina lutea (Table 3). C. album extractives were evaluated against five gram positive and eight gram negative bacteria. The test samples of $C$. album displayed zone of inhibition ranging from 7.0 to $13.0 \mathrm{~mm}$. The highest zone of inhibition $(13.0 \mathrm{~mm})$ was showed by the chloroform soluble fraction against Salmonella paratyphi (Table 4). Standard antibiotic, Ciprofloxacin was involved as the reference standard in this assay.

\section{Conclusion}

It is clearly evident from the above findings that both the test samples of C. bicolor and C. album have significant membrane stabilizing potentials. Furthermore, C. bicolor and C. album extractives demonstrated mild to moderate antimicrobial activity. Therefore, both the plants are good candidates for further systematic, chemical and biological studies to isolate the active principles.

\section{References}

[1] Adamu, H.M., Abayeh, O.J., Agho, M.O., Abdullahi, A.L., Uba, A., Dukku, H.U. and Wufem, B.M., An ethnobotanical survey of Bauchi State herbal plants and their antimicrobial activity, J Ethnopharmacol, 99 (2004) 1-4.

[2] Rios J.L. and Recio, M.C., Medicinal plants and antimicrobial activity, J Ethnopharmacol, 100 (2005) $80-84$.

[3] Chowdhury, J.A., Islam, M.S., Asifuzzaman, Sk. and Islam, M.K., Antibacterial and cytotoxic activity screening of leaf extracts of Vitex negundo (Fam: Verbenaceae), J Pharm Sci \& Res, 1(4) (2009) 103-8.

[4] Cragg, G.M., Newman, D.J. and Snader, K.M., Natural products in drug discovery and development, J Nat Prod, 60 (1997) 52- 60.

[5] Madison, M., Notes on Caladium (Araceae) and its allies, Selbyana, 5(3, 4) (1981) 342-77.

[6] Resslar, P.M., Observing caladiums in the Northern Range of Trinidad, Selbyana, 927(1) (2006) 93-5.

[7] Luu, C., Contribution à l'étude des plantes médicinales de la Guyane Francaise, Journal d'Agriculture Tropicale et de Botanique Appliqué, 22(4-6) (1975) 121-41.

[8] Yadav, N., Vasudeva, N., Singh, S. and Sharma, S. K., Medicinal prooerties of genus Chenopodium Linn., Nat Prod Rad, 6(2) (2007) 131-34.

[9] Hossain, S.M., Islam, F., Sharmin, T., Sheikh, H., Hasan, A.M.R. and Rashid, M.A., In vitro Antioxidant, Membrane Stabilizing and Thrombolytic Activities of Glycosmis arborea, Bang Pharm J, 15(2) (2012) 141-43.

[10] Sarker, R., Sharmin, T., Chowdhury, S.R. and Islam, F., Thrombolytic Activity and Preliminary Cytotoxicity of Five Different Fractions of Methanol Extract of Allamanda cathartica Leaf, J App Pharm Sci, 2(7) (2012) 129-32.

[11] Islam, F., Chowdhury, S.R., Sharmin, T., Uddin, M.G., Kaisar, M.A. and Rashid, M.A., In Vitro Membrane Stabilizing and Thrombolytic Activities of Ophirrhiza mungos, Mussaenda macrophylla, Gmelina philippensis and Synedrella nodiflora Growing in Bangladesh, J Phar Nutri Sci, 3 (2013) 71-5.

[12] Mita, T.A., Shihan, M.H., Rahman, M., Sharmin, T., Maleque, M. Alvi, M.R.H. and Chowdhury, S.R., In Vitro Antioxidant, Cytotoxic, Thrombolytic, Antimicrobial and Membrane Stabilizing Activities of Murraya paniculata, Am J Res Commun, 1(5) (2013) 226-37.

[13] Sharmin, T., Islam, F., Kaisar, M.A., Uddin, M.G. and Rashid, M.A., Antioxidant, Thrombolytic and Cytotoxic Activities of Picrasma javanica, Dhaka Univ J Pharm Sci, 11 (2012) 71-4.

[14] Sharmin, T., Islam, F., Sikder, M.A., Kabir, S., Haque, M.R. and Rashid, M.A., Membrane Stabilizing and Preliminary Hypoglycemic Activities of Picrasma javanica, Bang Pharm J, 16(1) (2013) 89-92.

[15] Vanwagenen, B.C., Larsen, R., Cardellina, J.H., Randazzo, D., Lidert, Z.C. and Swithenbank, C., Ulosantoin, a potent insecticide from the sponge Ulosa ruetzleri, J Org Chem, 58 (1993) 335-37.

[16] Omale, J. and Okafor, P.N., Comparative antioxidant capacity, membrane stabilization, polyphenols composition and cytotoxicity of the leaf and stem of Cissus multistriata, Afr J Biotechnol, 7, (2008) 3129-33.

[17] Bayer A W, Kirby W M M, Sherris J C and Turck M., Antibiotic susceptibility testing by a standardized single disc method, Am J Clin Pathol, 45 (1966) 493-496. 